\title{
Development and assessment of multiplex high resolution melting assay as a tool for rapid single-tube identification of five Brucella species
}

\author{
Krishna K Gopaul ${ }^{1 *}$, Jessica Sells ${ }^{1,3}$, Robin Lee ${ }^{1}$, Stephen M Beckstrom- Sternberg ${ }^{2}$, Jeffrey T Foster ${ }^{2,4}$ \\ and Adrian M Whatmore ${ }^{1}$
}

\begin{abstract}
Background: The zoonosis brucellosis causes economically significant reproductive problems in livestock and potentially debilitating disease of humans. Although the causative agent, organisms from the genus Brucella, can be differentiated into a number of species based on phenotypic characteristics, there are also significant differences in genotype that are concordant with individual species. This paper describes the development of a five target multiplex assay to identify five terrestrial Brucella species using real-time polymerase chain reaction (PCR) and subsequent high resolution melt curve analysis. This technology offers a robust and cost effective alternative to previously described hydrolysis-probe Single Nucleotide Polymorphism (SNP)-based species defining assays.

Results: Through the use of Brucella whole genome sequencing five species defining SNPs were identified. Individual HRM assays were developed to these target these changes and, following optimisation of primer concentrations, it was possible to multiplex all five assays in a single tube. In a validation exercise using a panel of 135 Brucella strains of terrestrial and marine origin, it was possible to distinguish the five target species from the other species within this panel.

Conclusion: The HRM multiplex offers a number of diagnostic advantages over previously described SNP-based typing approaches. Further, and uniquely for HRM, the successful multiplexing of five assays in a single tube allowing differentiation of five Brucella species in the diagnostic laboratory in a cost-effective and timely manner is described. However there are possible limitations to using this platform on DNA extractions direct from clinical material.
\end{abstract}

Keywords: High Resolution Melting (HRM), Brucella, Species identification, Typing, Real time PCR

\section{Background}

Brucellosis is a zoonosis of great socio-economic importance that causes reproductive problems including abortions and sterility in large livestock such as cattle, sheep, pigs and goats [1]. In humans, brucellosis can manifest itself in many disparate ailments such as general malaise, fever and arthritis in chronic cases [2]. Transmission from animal to human is facilitated through contact with, or ingestion of, infected material such as abortion tissue or unpasteurised milk from infected animals [2].

The causative agents of brucellosis are organisms from the genus Brucella. There are eight recognised species

\footnotetext{
* Correspondence: Krishna.Gopaul@apha.gsi.gov.uk

${ }^{1}$ Department of Bacteriology, Animal and Plant Health Agency, Woodham

Lane, New Haw, Addlestone, Surrey KT15 3NB, UK

Full list of author information is available at the end of the article
}

within the genus that have been associated with brucellosis in various terrestrial mammals and at least a further two species associated with marine mammals [3]. However the genus is expanding and recent isolations from baboons, foxes, and frogs suggest that are more groups awaiting description [4-6].

Classically, Brucella species are defined through a combination of perceived host specificity and phenotypic characterisation. In this way, $B$. abortus is typically associated with brucellosis in bovines, $B$. melitensis with brucellosis in caprines and ovines, $B$. suis with brucellosis in swine and $B$. canis with canine brucellosis [3]. In ovines, $B$. ovis manifests as ovine epididymitis in rams [1]. However there have been isolations of Brucella species outside their perceived hosts, for example, B. melitensis infection of cattle being reported $[7,8]$. 
In terms of diagnosis, molecular techniques have been developed for the rapid identification of Brucella spp based on genus conserved targets such as bcsp31 [9] and IS711 $[10,11]$. As these assays use DNA and not viable bacteria, molecular methods for Brucella diagnosis can be more safely used in a wider range of laboratories. Furthermore, there are also molecular tests available that have been developed that can rapidly discriminate to species level from a primary isolation [9,12-17].

Whilst a number of these tests have been described in the literature, there are two main groups. One group of assays uses specific insertions/deletions identified through genome characterisation of a number of Brucella species. These tests include techniques such as AMOS PCR and Bruceladder [12-14] based on a conventional PCR platform as well as assays such as those described by Redkar et al., [15] and Probert et al., [9] using a real time PCR platform. The second group makes use of single nucleotide polymorphisms (SNPs) identified through MultiLocus Sequence Analysis (MLSA) using hundreds of Brucella strains from all species [18] or through whole genome sequencing. Currently, all recognised and proposed Brucella species have been identified with unique MLSA sequence types [4-6,18] and assays have mostly been developed using real-time PCR platforms and probe based technologies [16,17]. Although these assays have proven highly effective their implementation is hindered by the expense associated with dual labelled hydrolysis probe multiplexes $[16,17]$ that make this type of testing potentially difficult to apply in resource limited regions.

One alternative to using hydrolysis probe chemistry is to use melt curves to determine the presence or absence of a target SNP within an otherwise conserved region of sequence $[19,20]$. In this scheme, during amplification, an intercalating dye (typically SYBR green) binds to double stranded DNA that forms, generating a fluorescence reading. In the melt cycle, with the increase of temperature, the double stranded product begins to separate and fluorescence drops. The melt peak (which is related to the DNA composition of the product) occurs at a point where $50 \%$ of the product population is double stranded and $50 \%$ single stranded. Changes in the sequence alter the melt temperature of the target. The major advantage of this methodology over probe-based genotyping is that the chemistry utilised is much cheaper, although this approach has previously suffered from its inability to detect very subtle but significant changes in melt temperatures [21] Nevertheless, recent advances in both dye chemistry and hardware, leading to the development of High Resolution Melt (HRM) curve analysis, facilitates detection of much smaller differences in temperature than previously achieved [22]. Indeed, HRM as a tool for genotyping has been shown to be of great utility [23] not only for bacteria [24,25] but also for viruses [26] and eukaryote parasites [27]. Furthermore, with pathogen detection and genotyping, there are many examples in the literature of the application of HRM for human genetics to characterise genetic variation linked with various cancers [28,29] and other ailments [30,31].

One previous study has described the use of HRM for Brucella species identification [32]. However, as in the case of the majority of other publications using HRM for genotyping, this previous study described using one or a number of singular reactions for differentiation. This type of approach in turn reduces the throughput of the system making it less attractive for implementation. Therefore the intention of this study was not only to develop HRM assays as an alternative means of SNP-based Brucella species determination but to also combine HRM assays in one tube to improve throughput. To this end this paper describes the creation of a quintuplex test that can rapidly, cheaply and unambiguously define strain identity for five terrestrial Brucella species of agro-economic importance; B. abortus, B. canis, B. melitensis, B. ovis and $B$. suis. Of these five species $B$. melitensis, B. abortus and $B$. suis are the species associated with most economically significant animal and human disease [1]. Concerning the remaining two species, $B$. canis infects dogs and is occasional cause of human infection whilst $B$. ovis is a minor and far less-widely distributed animal pathogen.

\section{Results}

\section{Identification of target SNPs}

From multi-locus sequence analysis work described previously a number of SNPs that define particular Brucella species have been identified [18]. This extensive work examining a spatially and temporally diverse panel of $>700$ Brucella strains of all Brucella species provided the basis for the subsequent multiple outcome species defining assays based on Minor Groove Binding (MGB) TaqMan ${ }^{\odot}$ probe chemistry [17]. It was therefore initially thought that the same targets could be as the basis of the HRM assays. However using the selection criteria described in the methods section, it was found that none of the previously used targets were suitable markers for use in HRM assays.

It was therefore decided to make use of the expanding Brucella whole genome sequence (WGS) project database, hosted by the Broad Institute, Massachusetts, USA. Although this database is not currently as diverse and large as the in-house MLSA, it does none the less provide enough variation (in terms of Brucella species) to identify potential markers. Through alignments of 35 Brucella spp genome sequences available from the WGS project in March 2010 (Table 1), potential canonical SNPs for the determination of the five targeted Brucella species were identified based on location in B. melitensis $16 \mathrm{M}$. Using these data, regions flanking these SNPs were identified 
Table 1 A breakdown of the 35 Brucella genomes used for SNP discovery of species specific targets

\begin{tabular}{lc}
\hline Brucella species & Number of complete genomes available \\
\hline B. abortus & 9 \\
B. canis & 1 \\
B. ceti & 5 \\
B. inopinata & 1 \\
B. melitensis & 4 \\
B. microti & 1 \\
B. neotomae & 1 \\
B. ovis & 1 \\
B. pinnipedialis & 3 \\
B. suis & 5 \\
Atypical Brucella & 4 \\
\hline
\end{tabular}

and tested in silico for secondary structure and melt to see if they met the required criteria. Primers for those regions deemed useful were then designed and tested on a small panel of isolates comprising the type strains for B. abortus, B. melitensis, B. ovis and B. canis (Table 2).

\section{Titration work}

To determine the sensitivity of discrimination of HRM assays, titrations of the genomic DNA from the five target Brucella species were prepared and tested. Through titrations it was determined that the limit for reproducible discrimination of the five individual HRM assays was $100 \mathrm{fg}$ (data not shown). It was noted that whilst using the negative first derivative of the data, there was no difference in the positioning of melt peaks with changing DNA concentration (Figure 1), there were changes in the kinetics of the melt curve with DNA concentration (Figure 2). As interpretation of the quintuplex was performed visually (Figures 3 and 4), comparing the curve dynamic of the sample with that of a known control on the same run, low concentrations of non-target Brucella could be misinterpreted as high concentrations of the target species. In a review of HRM, Reed et al. [33] mentioned that interpretation of HRM data was better achieved through the comparison of melt curves rather than from the first derivative melt peak which was subject to "data smoothing". It was for this reason that the decision was made to standardise the amount of DNA tested to $1 \mathrm{ng} / \mu \mathrm{l}$ in subsequent work.

\section{Development and validation of the quintuplex}

Results of individual reactions for the five species-defining assays demonstrated that the technique was promising, although the issue of change in melt dynamic with the variation in the amount of template added was of concern. However, it was the intention from the conception of this work to develop a species-defining quintuplex. This in turn meant that there had to be 10 distinct melting temperatures to account for each species specific and non-species specific melt. To do this, the melting temperatures of the products of each assay were manipulated to defined melt temperatures by adjusting product size to ensure no overlap between each individual melt peak that would render sample identification impossible. The concentrations of primers added to the primer mix were meticulously optimised to ensure high quality and equally sized melt curves were generated for each speciesdefining assay in the quintuplex. It was observed that each of the species tested produced a distinct curve profile and that those profiles of isolates not belonging to one of the included five Brucella species, such as B. microti, are also distinct (Figures 3 and 5).

In the validation of the quintuplex assay, highly purified DNA from 135 isolates that had previously been identified using both classical biotyping and the TaqMan probe based real-time PCR approach (Table 3 for panel breakdown and Additional file 1 for complete strain identity) were tested with the HRM multiplex assays. These isolates were chosen to reflect the genetic diversity of the Brucella species in question based on previous MLSA studies [18]. The results of the HRM work were that all 135 samples tested gave species identification congruent with phenotypic and real-time PCR testing [17] (data not shown).

\section{Specificity testing of Brucella spp assays}

To determine the specificity of published Brucella genus molecular diagnostics in an expanding Brucellaceae family, two real time PCR assays based on the IS711 target $[10,11]$ and one based on the $b c s p 31$ target [9] were used to test a panel of 23 non-Brucella Brucellaceae (Table 4). It was found that there were no false positive results generated with any of the three assays generated (data not shown), proving that these assays were specific to Brucella genus organisms within the Brucellaceae family.

\section{Discussion}

\section{Assay performance}

From the testing of 135 Brucella isolates, it was observed that the HRM targets and assays correctly identified all isolates to the corresponding species, or in the cases of B. ceti, B. inopinata, B. microti, B. neotomae, and $B$. pinnipedialis as not being members of one of the species included in the assay. These findings were encouraging as although SNPs derived through Brucella MLSA work [18] had been rigorously tested with the sequencing of hundreds of Brucella strains, the SNPs identified by whole genome sequencing had been selected after comparison with a much smaller group of 35 sequenced Brucella genomes. Although the test panel chosen for this work is relatively small, the selection and testing of a wide number of Brucella MLSA sequence types shows the robustness of the SNPs chosen. 
Table 2 Targets, primer sequences and final concentrations for each of the species-specific quintuplex HRM assays

\begin{tabular}{|c|c|c|c|c|c|}
\hline Brucella species & Forward primer sequence & Reverse primer sequence & $\begin{array}{l}\text { Final concentration of primer } \\
\text { pair in quintuplex reaction }(\mu \mathrm{M})\end{array}$ & Product size (bp) & Gene target (based on B. abortus 9-941) \\
\hline B. abortus & 5'-GCCCCTCCTTCTTGTAATCA-3' & 5'-ACCATGAAGAAAGCGCGTAT-3' & $1.25 \mu \mathrm{M}$ & 75 & BruAb1_0395Hypothetical protein \\
\hline B. melitensis & 5'-ACAAGCTGACGAAGGACCAT-3' & 5'-CCCGTATAGGAGTGGATCGT- 3' & $0.5 \mu \mathrm{M}$ & 135 & $\begin{array}{l}\text { BruAb1_1713 glyceraldehyde-3-phosphate } \\
\text { dehydrogenase }\end{array}$ \\
\hline B. ovis & 5'-CCGGTCAAGTTCAATCACG-3' & 5'-GCTGGAAATGCTCTATTACTC-3' & $1 \mu \mathrm{M}$ & 66 & BruAb1_1179 Hypothetical protein \\
\hline B. suis & 5'-CTGGCGGAAAAGGATTTGAT-3' & 5'-AATCACGACAAACCACAGCA-3' & $1.125 \mu \mathrm{M}$ & 89 & $\begin{array}{l}\text { BruAb1_1338 Sugar ABC transporter, } \\
\text { permeaseprotein }\end{array}$ \\
\hline B. canis & 5'-CCCCCGTCAATTCCTGCCGAA-3' & 5'-CCCCCGTGGCCTGGTCGAGAT-3' & $0.25 \mu \mathrm{M}$ & 79 & $\begin{array}{l}\text { BruAb2_1115 Transcriptional regulator } \\
\text { (GntR Family) }\end{array}$ \\
\hline
\end{tabular}




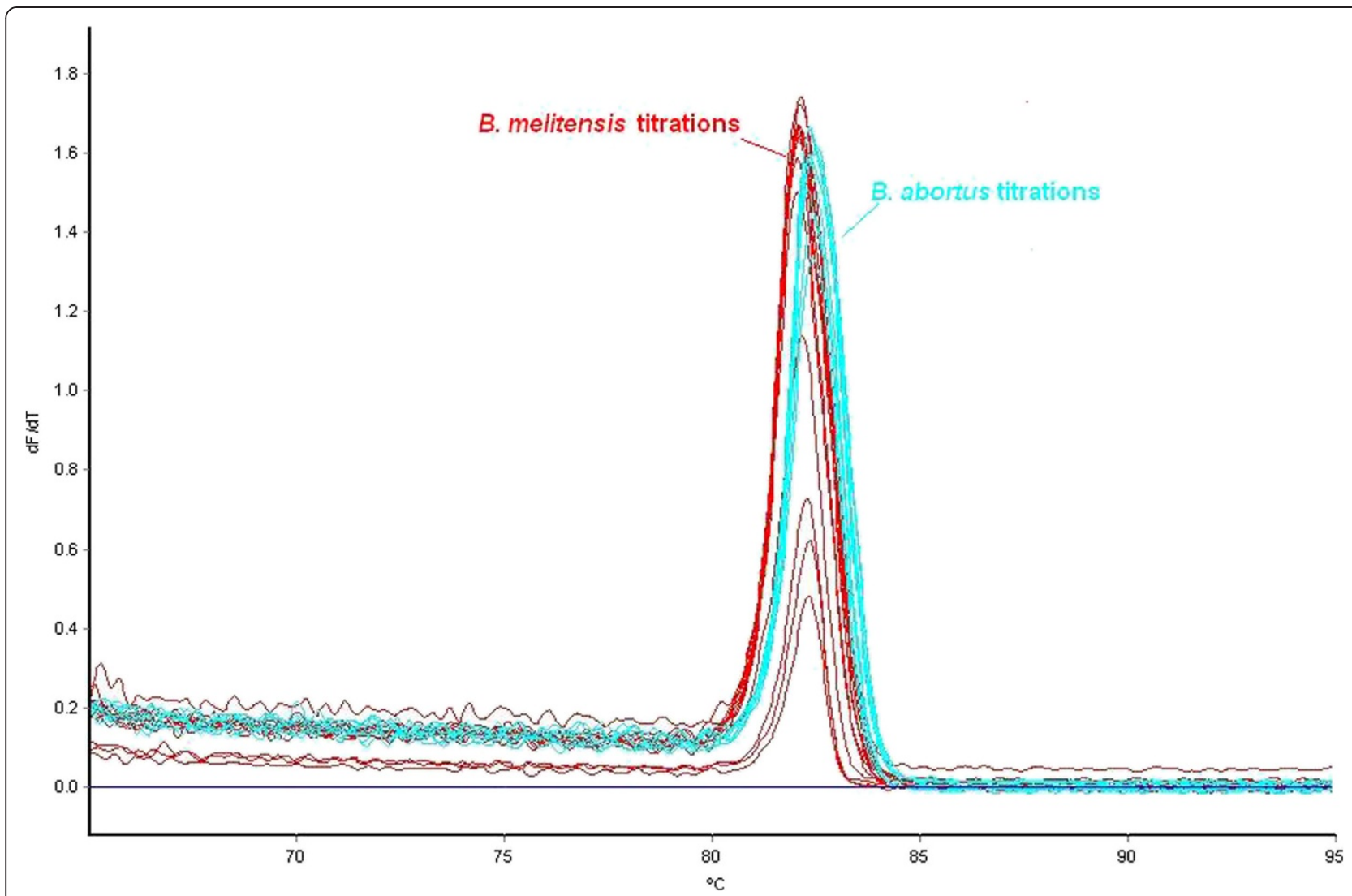

Figure 1 Melt peaks of one HRM assay with titrations of target and non target DNA. The results of a titration range of $1 \mathrm{ng}-100 \mathrm{fg}$ genomic DNA from B. melitensis $16 \mathrm{M}$ (red) and B. abortus 544 (blue) using the B. melitensis HRM assay and the negative first derivative melt peak data. As shown, whilst the peak size does vary with the concentration of DNA, there is clear differentiation between the two species.

The HRM method offers a simple solution to SNP-based genotyping, with little downstream processing and a closed tube excluding the hazards of product manipulation and possible subsequent cross-contamination. In terms of analysis, data acquisition is rapid with a melt only taking a few minutes post amplification. Data analysis is straightforward with species assignment based on a visual comparison of curve kinetics with reference strains on the same run (Figure 3). Although there is an upfront hardware cost, once purchased reagent prices are lower than those associated with Taqman-probe based SNP typing. In addition, the testing for five Brucella species in one tube gives equivalent resolution but at five times the throughput of individual assays such as those based on the use of hydrolysis probes $[17,18]$. This is yet another cost reduction measure presented by this HRM assay that makes the use of SNPs for the identification of Brucella sequences more attractive.

In this study, the focus has been on the development of a quintuplex focusing on five species that commonly infect animals of agro-economic importance. However, this work should also been seen as a proof of concept, highlighting the possibility of multiplexing several SNPbased species defining assays for better throughput and reduced costs. Although other studies have also demonstrated the possibility of multiplexing HRM assays in triplex and quadruplex format $[34,35]$, this present work is an example where five individual bacterial targets have been characterised simultaneously in a single tube.

\section{Comparison with other Brucella HRM assays}

As mentioned earlier, the Brucella quintuplex HRM is not the first example of the application of HRM for the identification of Brucella species. Work published by Winchell et al., [32] described the application of a number of assays to comprehensively cover all known Brucella species with the exception of B. inopinata. Further, the incorporation of an assay for the direct identification of members of the Brucella genus allows for direct identification from isolation, something that is not available using the Brucella quintuplex. However, in defence of the quintuplex, it should be stated that there are already a number of Brucella real time PCR diagnostic assays available that have been validated on large panels of nonBrucella organisms [9-11]. Any of these assays could be used as a rapid screen to identify Brucella spp organisms. Indeed, work undertaken within this department using a 




Figure 2 Melt curves of one HRM assay with titrations of target and non target DNA. The results of a titration range of $1 \mathrm{ng}-100 \mathrm{fg}$ genomic DNA from B. melitensis $16 \mathrm{M}$ (red) and B. abortus 544 (blue) using the B. melitensis HRM assay and the HRM melt curves directly. Curves move from right to left with decreasing DNA concentration. As shown, the curves generated by very low concentrations of $B$. abortus DNA are very close to the curves generated by high concentrations of $B$. melitensis DNA and could be misidentified through this association.

number of non-Brucella Brucellaceae (Table 3) and three published assays based on IS711 [10,11] and bcsp31 [9] has shown that these assays are Brucella spp specific even in light of an expanding Brucellaceae genus (data not shown) and thus, these assays could be used as an initial screen for Brucella organisms prior to species differentiation.

In terms of targets, whilst both schemes use individual SNPs for each species, the Winchell paper also includes one target for two species; the gene glk for B. abortus and B. ovis [32]. From MLSA data it can be seen that whilst a majority of $B$. abortus strains tested do contain the SNP identified as B. abortus specific by Winchell et al., [32] a significant subset of isolates of African origin, including $B$. abortus biovar 3 type strain and field isolations of $B$. abortus biovars 3 and 6 have the alternate state SNP [18]. Further, to compound the issue, the SNP identified by Winchell et al. [32], as specific to B. neotomae is also found in the $B$. abortus biovar 3 type strain, leading to a possible misidentification with this HRM assay, Winchell et al. [32] do not state whether the $B$. abortus biovar 3 strain used was the type strain or a field isolation but this one example highlights a potential limitation in the universal applicability of this scheme.

Another major difference between the previously published Brucella HRM assay and the proposed quintuplex is the used of an insertion rather than a SNP to positively identify B. suis isolates in the former. From the SNPs identified in the MLSA work published by Whatmore et al., [18] it was not possible to identify a B. suis specific SNP that positively identified all five $B$. suis biovars but excluded B. canis. This reflects the phylogenetic placement of $B$. canis as a terminal node within the B. suis clade. However, the authors also mention that they could not differentiate $B$. suis biovar 4 from $B$. canis isolates, meaning that there could be misidentifications between certain $B$. suis and $B$. canis isolations. In comparison, the Brucella quintuplex uses SNPs derived from whole genome sequencing for the identification of all B. suis biovars and it has been shown to identify type strains from all five biovars in addition to clinical isolations. This is an improvement over previous hydrolysis probe based Brucella SNP assays that could not identify B. suis biovar 5 . Previous molecular 


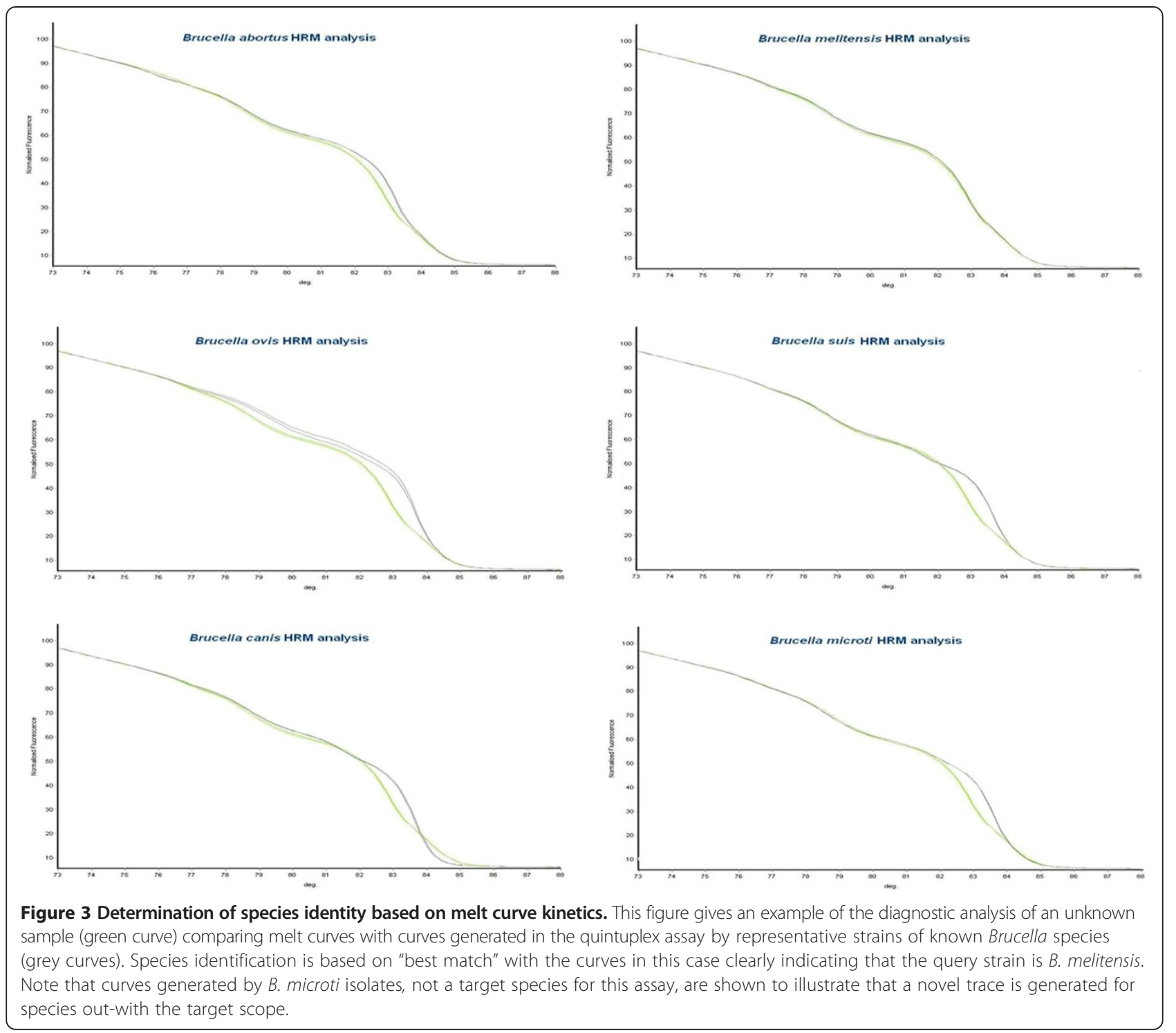

studies using variable number tandem repeat (VNTR) analysis and MLSA had suggested that $B$. suis biovar 5 might be considered a novel Brucella species $[18,36]$ although recent WGS analysis does confirm the placement of $B$. suis biovar 5 as a very early branch in the $B$. suis/B. canis clade $[37,38]$. Though $B$. canis shares this SNP, the quintuplex makes use of a unique $B$. canis SNP to separate this species, and despite this being an indirect testing algorithm it at least excludes the possibility of samples being misidentified.

\section{Issues with the use of HRM}

Although the reagent costs of running HRM assays are significantly cheaper than that of the equivalent hydrolysis probe real-time PCR tests, there are some issues that could potentially diminish the usefulness HRM for typing. Although the design process for HRM primers is straightforward, target choice is hampered by the need for minimum secondary structure. Evidence of this has been seen early in this current study with the inability to design HRM assays to targets previously used for hydrolysis probe based assays [17].

Further, this technique cannot identify the location of target SNP and so if there is a substitution that causes identical change in melt temperature elsewhere in the fragment other than the region of interest, this will be miscalled. Nevertheless, the known lack of genetic diversity in classical Brucella species [3] suggests this is unlikely to be an issue for Brucella spp HRM assay development.

In this study, it was observed that when titrations of different Brucella species were compared the limit of reproducible species identification for each of the five individual HRM assays was $100 \mathrm{fg}$ or approximately 30 bacterial cells. Winchell et al., [32] also found that this 


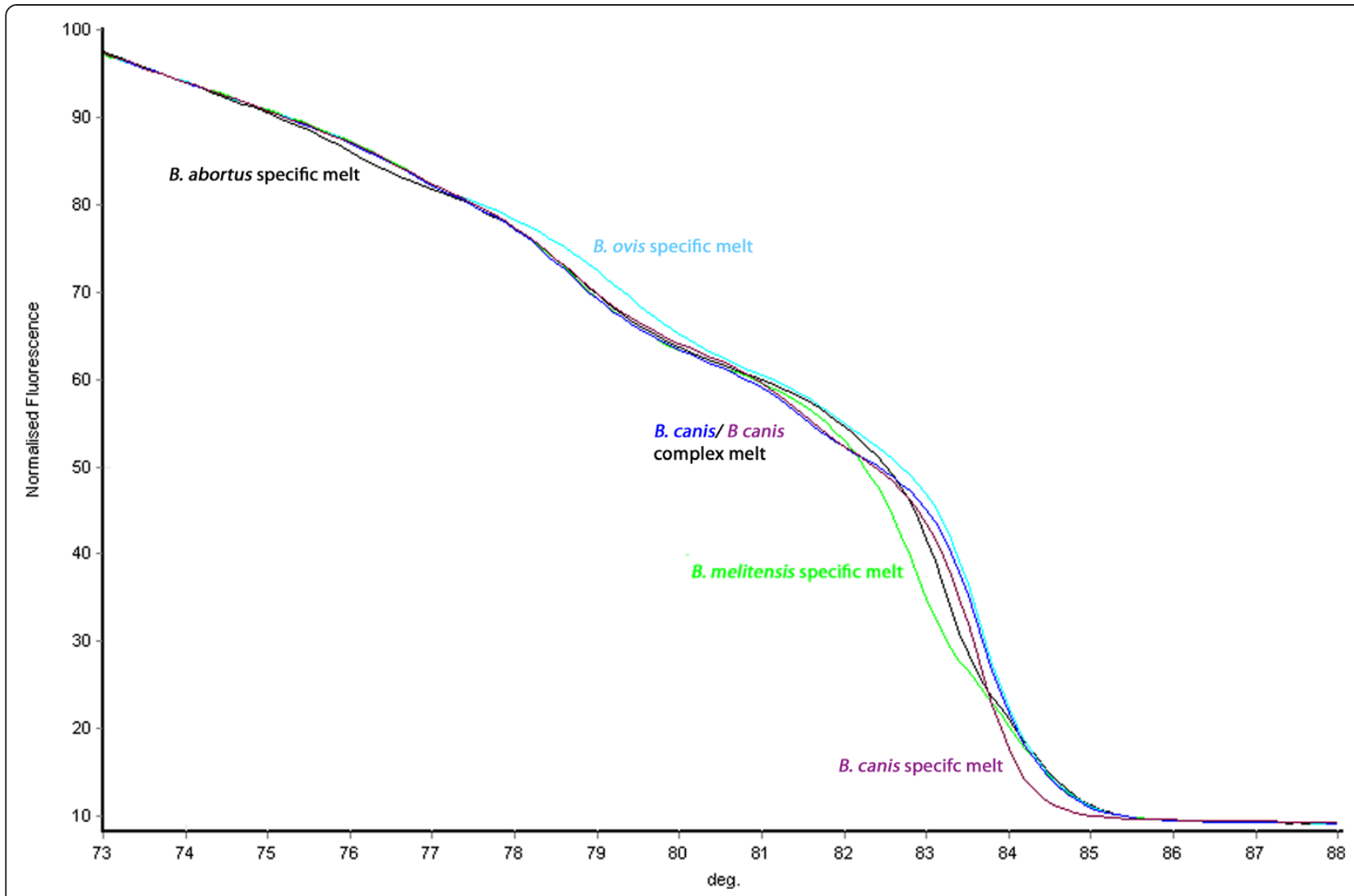

Figure 4 Melt curve kinetics for quintuplex target species. Melt profiles illustrating the unique HRM curves generated by the quintuplex for B. abortus (black), B. melitensis (green), B. ovis (light blue), B. suis (dark blue) and B. canis (purple). Each region of differentiation is highlighted.

level of sensitivity in the majority of assays tested and suggested that there may be a role for this type of testing in the direct typing of Brucella species from clinical material. However, whilst the sensitivity of the technique in determining species from purified DNA is clear, there are doubts as to the usefulness of HRM assays where the input DNA is not quantified. In this study, from the tests of titrations of target DNA as well as in other published work on HRM $[21,25,30]$, it was shown that melt curve characteristics are affected by the initial concentration of DNA template in the reaction. Another worrying observation reported in relation to the previously published Brucella HRM assay was the greater amount of DNA required for reproducible identification using the B. melitensis assay [32], intimating that at lower concentrations, incorrect typing results may be obtained. Whilst DNA quantification is straightforward in the case of test application following bacterial isolation, this would be problematic in field samples where the large excess of host DNA makes quantification of pathogen DNA impossible. In contrast, prior DNA quantification is not an issue for SNP based typing using hydrolysis probes. If a sample is positive using Brucella spp real time PCR assays, in theory it should be possible to undertake SNP typing using hydrolysis probes.
A further drawback is the fact that the melting temperature of DNA in this technique is not only dependant on the concentration of template pre-amplification but also on ionic conditions [21]. In turn this means not only does the sample need quantification preamplification but that the extraction methods and how the sample storage matrices. This may have implications for the type of sample that can be tested using this technique, with crude extractions (e.g. heat inactivated cells) possibly being problematic. However, this can be rectified by running these extractions thorough a commercial DNA extraction kit.

In spite of these issues, the demonstration of the possibility to multiplex SNP-based HRM assays is a major selling point for this technology. In contrast, the rigidness of the two fluorophore hydrolysis probe method only allows for two possible outcomes per reaction; does this sample possess or lack the SNP that is targeted in this reaction. However, whilst the HRM method does improve throughput by the combination of assays, it should be noted that this method described in this paper requires the use of known Brucella strains in every run to allow for comparison with unknown samples. 


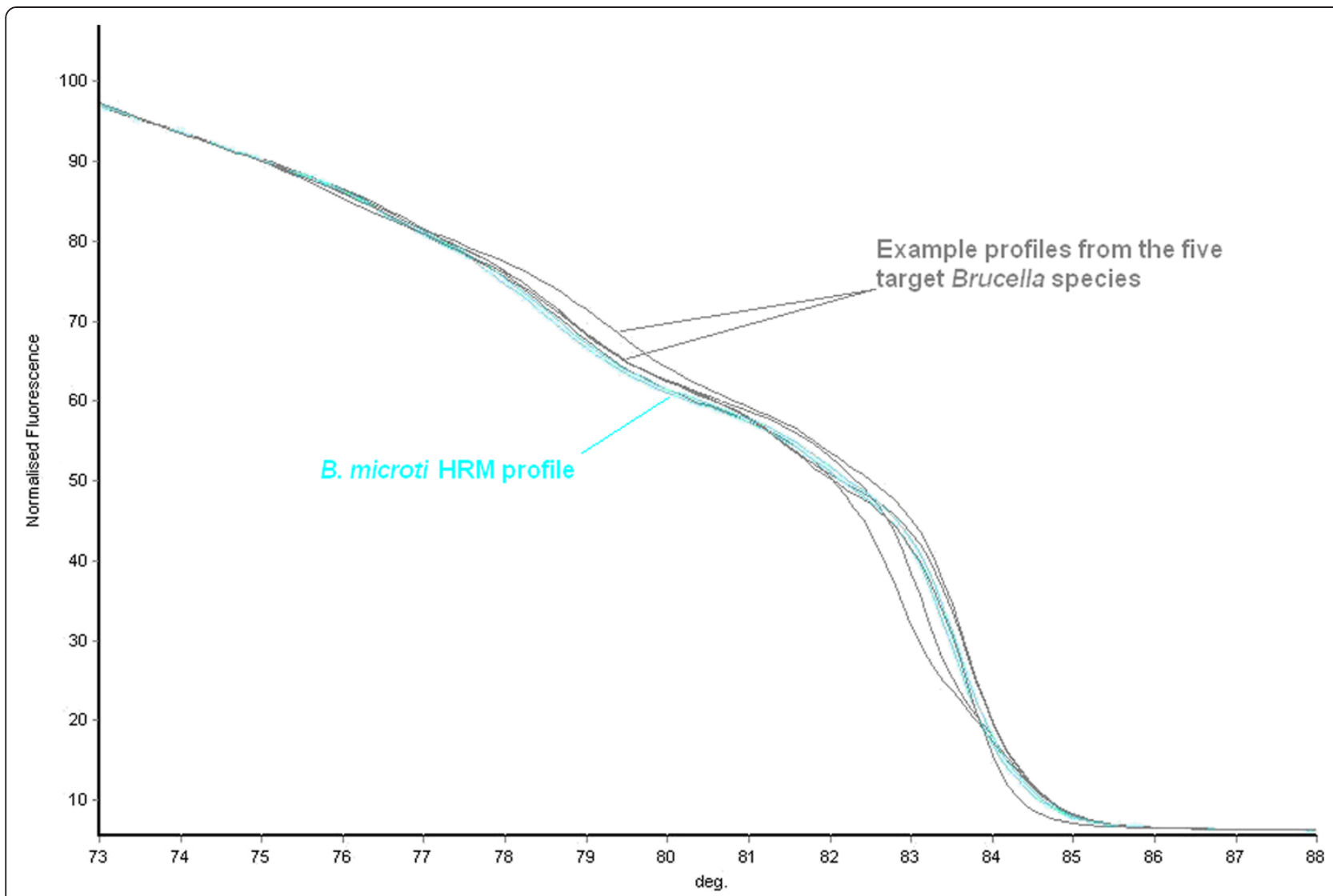

Figure 5 Melt curve kinetics for quintuplex non target species. This figure illustrates how a Brucella isolate that is not a member of one of the five major species would be excluded by this assay. The curves in grey are traces from the five species targeted by the quintuplex whilst the traces in blue represent a non-target Brucella species (in this case B. microti). The blue traces are not congruent with any of the grey traces indicting that the sample tested represents a species not included in this assay.

Table 3 A breakdown of the 135 Brucella strains used in the validation of the HRM quintuplex

\begin{tabular}{lc}
\hline Brucella species/type & Number of strains tested \\
\hline B. abortus & 23 \\
B. canis & 9 \\
B. ceti & 10 \\
B. inopinata & 1 \\
B. melitensis & 47 \\
B. microti & 1 \\
B. neotomae & 1 \\
B. ovis & 20 \\
B. pinnipedialis & 9 \\
B. suis & 13 \\
Atypical Brucella & 1 \\
Total & $\mathbf{1 3 5}$ \\
\hline
\end{tabular}

One final issue in the use of HRM is the ability to multiplex reactions to allow for "one tube" species identification on a real-time PCR platform. In this study, five targets were combined to allow for the identification of five terrestrial Brucella species. This was done through the variation of the product sizes and primer concentrations for each of the assays used. There are SNPs that can identify all recognised Brucella species (currently ten in total) and vaccine strains $[18,39$, A. M. Whatmore and M. S. Koylass unpublished data]. Nevertheless, although it has been suggested that larger multiplex reactions may be possible [35], given the way the data is currently analysed in the quintuplex, the addition of further Brucella targets for vaccines and other species to the described assay may make the interpretation of data generated more difficult and thus, full characterisation may require the running of several HRM multiplex reactions.

\section{Conclusion}

In conclusion, the HRM technique is a highly accurate method for typing Brucella to species level based on single diagnostic SNPs. It is a simple and rapid closed tube 


\begin{tabular}{ll} 
Table 4 A list of non- Brucella Brucellaceae used to \\
determine the specificity of three published \\
assucella spp \\
\hline Name & Strain number \\
\hline Ochrobactrum anthropi & LMG 3331 \\
Ochrobactrum ciceri & DSM 22292 \\
Ochrobactrum cytisi & DSM 19778 \\
Ochrobactrum daejeonense & JCM 16234 \\
Ochrobactrum gallinifaecis & DSM 15295 \\
Ochrobactrum grignonense & LMG 18954 \\
Ochrobactrum haematophilum & CIP 109452 \\
Ochrobactrum intermedium & LMG 3301 \\
Ochrobactrum lupini & DSM 16930 \\
Ochrobactrum oryzae & DSM 17471 \\
Ochrobactrum pecoris & CCUG 60088 \\
Ochrobactrum pituitosum & DSM 22207 \\
Ochrobactrum pseudogrignonense & CIP 109451 \\
Ochrobactrum pseudintermedium & DSM 17490 \\
Ochrobactrum rhizosphaerae & DSM 19824 \\
Ochrobactrum thiophenivorans & DSM 7216 \\
Ochrobactrum tritici & LMG 18957 \\
Paenochrobactrum gallinarii & CCUG 57736 \\
Paenochrobactrum glaciei & JCM 15115 \\
Pseudochrobactrum asaccharolyticum & CCUG 46016 \\
Pseudochrobactrum kiredijianiae & DSM 19762 \\
Pseudochrobactrum lubricatis & CCUG 56963 \\
& CCUG 33852 \\
\hline
\end{tabular}

test with minimal risks of cross-contamination. Assay design is straight forward using freeware tools and the chemistry utilised is much cheaper to run than the chemistry utilised by hydrolysis-probe mediated SNP identification, allowing for wider use of Brucella SNPs for molecular-based species identification. In this study, through optimisation of primer concentrations, it was possible to multiplex five Brucella species-identifying HRM assays in one tube allowed for a much higher throughput than the equivalent assays based on hydrolysis probe chemistry. Although limitations in the number of targets that can be multiplexed in one reaction have been identified, the HRM platform is open and there is the potential to add further Brucella SNP-based HRM assays to allow for more comprehensive identification.

However, whilst the quintuplex provides a useful and cheaper alternative to that of hydrolysis probes for realtime SNP typing when applied to bacterial culture material, these techniques may not be appropriate for direct testing from clinical material as there are constraints regarding condition quantification of DNA samples prior to amplification.

\section{Methods}

SNP discovery and assay development

Data from both the AHVLA Brucella MLSA scheme and from an international whole genome sequencing project hosted by the Broad Institute, Cambridge, USA (http:// www.broadinstitute.org/annotation/genome/brucella_group/ MultiHome.html) were used to identify SNPs (and associated flanking sequence of $100 \mathrm{bp}$ ) specific to the five most significant Brucella species; B. abortus, B. melitensis, B. ovis, $B$. suis and B. canis. The criteria for target choice were the presence of only one known SNP per amplicon, and amplicon size of between $70 \mathrm{bp}$ and $250 \mathrm{bp}$. Overall amplicon sizes for the different species targets were staggered to allow for subsequent multiplexing of assays. Secondary structure in potential targets was determined using the DINAMelt programme available freely online (http:// mfold.rna.albany.edu/?q=DINAMelt) and regions with a change in Gibbs Free energy $(\Delta G)$ value $>-1$ were taken forward and used as the basis for subsequent primer design. Primers were then designed using the Primer 3 software (http://frodo.wi.mit.edu/primer3/). For each target selected, a number of primer combinations were generated by this software, synthesised and tested in simplex reactions.

\section{HRM reaction set up and analysis}

Reactions were run in a volume of $25 \mu \mathrm{l}$ using Qiagen Type-it $^{\circ}$ HRM $^{\mathrm{mi}}$ PCR mix (Qiagen, Crawley, West Sussex, United Kingdom). Each reaction contained final concentrations of 1x HRM Type-it ${ }^{\text {th }}$ mix (Qiagen, Crawley, West Sussex, United Kingdom) and $0.7 \mu \mathrm{M}$ forward and reverse primer (for each target). Each sample was tested in duplicate. Reactions were run on a Qiagen Rotorgene-Q 5-plex machine (Qiagen, Crawley, West Sussex, United Kingdom) with temperature cycling parameters for the amplification stage being a hold of $95^{\circ} \mathrm{C}$ for 5 minutes, followed by $40 \mathrm{cy}$ cles of $95^{\circ} \mathrm{C}$ for 10 seconds, $60^{\circ} \mathrm{C}$ for 30 seconds, and $72^{\circ} \mathrm{C}$ for 20 seconds. For the HRM stage, fluorescence recordings were made over the range of $65-95^{\circ} \mathrm{C}$ by increments of $0.1^{\circ} \mathrm{C}$. A normalised graph was generated using normalisation regions of $73-75^{\circ} \mathrm{C}$ and $86-88^{\circ} \mathrm{C}$.

To determine the sensitivity of differentiation, titrations of genomic DNA from four species (B. abortus, B. melitensis, B. ovis and B. suis) were prepared from $1 \mathrm{ng} / \mu \mathrm{l}$ to $100 \mathrm{ag} / \mu \mathrm{l}$ and tested with single HRM assays. For all subsequent work DNA samples were quantified and standardised to $1 \mathrm{ng} / \mu \mathrm{l}$ prior to testing.

Assays were first tested individually to determine suitability for further work. After the species specificity of each individual assay had been determined, multiplexing was attempted. With multiplexing of assays, only primer concentrations for the species-specific assays were varied to allow for optimum differentiation of samples from different Brucella species. Once concentrations of each assay 
used were optimised, a panel of DNA isolated from 135 Brucella isolates was selected to validate the multiplex (Table 2 for species composition; Additional file 1: Table S1 for further characterisation). The strains used in this study form part of a collection of bacterial isolations held at AHVLA. As only bacterial DNA from this collection was used as testing material, this work did not require approval through the AHVLA ethics committee. Strain identity was assigned based on the visual similarity of the melt curve generated by the unknown to melt curves generated by reference strains of the five target species. As there was no means of storing these reference curves generated for analysis over different runs it was necessary to include an example of each of the five target species in every run undertaken.

\section{Set up for Brucella spp real time PCR assays}

The real time PCR assays used for this section of this study were run as published [9-11] with the following amendments. For DNA template, $2 \mu \mathrm{l}$ of heat inactivated bacterial culture suspension was used for each of the Brucellaceae species tested (Table 4). This material was previously indentified and confirmed as being fit for PCR using 16SrRNA sequencing [40].

\section{Additional file}

Additional file 1: Table showing the test panel of 135 Brucella strains used for the validation of HRM quintuplex assay including full strain identity.

\section{Abbreviations}

bp: Base pairs; HRM: High resolution melting; MGB: Minor groove binding; MLSA: Multi locus sequence analysis; PCR: Polymerase chain reaction; SPP: Species; SNP: Single nucleotide polymorphism; ST: Sequence type; VNTR: Variable number tandem repeat; WGS: Whole genome sequencing.

\section{Competing interests}

The authors declare that they have no competing interests.

\section{Authors' contributions}

KKG, JS and AMW were involved in the conception and design of the study. $J S, R L$ and KKG were involved in the acquisition and analysis of the data generated in HRM testing. JTS and SMB-S provided SNP data generated through the whole genome sequencing of Brucella isolates. KKG and AMW were involved in the drafting of the manuscript with the help of comments from the remaining authors. All authors read and approved the final manuscript.

\section{Acknowledgements}

The authors would like to acknowledge Mr Jakub Muchowski for his help in the preparation of heat inactivated Brucellaceae samples for testing. This work was funded by the Department of the Environment and Rural Affairs (Defra) under projects ROAME SE0313 and SE0314.

\section{Author details}

${ }^{1}$ Department of Bacteriology, Animal and Plant Health Agency, Woodham Lane, New Haw, Addlestone, Surrey KT15 3NB, UK. ${ }^{2}$ Center for Microbial Genetics and Genomics, Northern Arizona University, Flagstaff, AZ 86011-4073, USA. ${ }^{3}$ Current address: MRC Prion Unit, Queen Square House, Queen Square, London WC1N 3BG, UK. ${ }^{4}$ Current address: Department of
Molecular, Cellular, \& Biomedical Sciences, University of New Hampshire, College Road, Durham, NH 03824, USA.

Received: 25 April 2014 Accepted: 28 November 2014 Published: 11 December 2014

\section{References}

1. Godfroid J, Nielsen K, Saegerman C: Diagnosis of brucellosis in livestock and wildlife. Croat Med J 2010, 51:296-305.

2. Seleem MN, Boyle SM, Sriranganathan N: Brucellosis: a re-emerging zoonosis. Vet Microbiol 2012, 140:392-398.

3. Whatmore AM: Current understanding of the genetic diversity of Brucella, an expanding genus of zoonotic pathogens. Infect Genet Evol 2009, 9:1168-1184.

4. Schlabritz-Loutsevich NE, Whatmore AM, Quance CR, Koylass MS, Cummins LB, Dick EJ Jr, Snider CL, Cappelli D, Ebersole JL, Nathanielsz PW, Hubbard GB: A novel Brucella isolate in association with two cases of stillbirth in non-human primates-first report. J Med Primatol 2009, 38:70-73.

5. Hofer E, Revilla-Fernández S, Al Dahouk S, Riehm JM, Nöckler K, Zygmunt MS, Cloeckaert A, Tomaso H, Scholz HC: A potential novel Brucella species isolated from mandibular lymph nodes of red foxes in Austria. Vet Microbiol 2012, 155:93-99.

6. Eisenberg T, Hamann HP, Kaim U, Schlez K, Seeger H, Schauerte N, Melzer F, Tomaso H, Scholz HC, Koylass MS, Whatmore AM, Zschöck M: Isolation of potentially novel Brucella spp. from frogs. Appl Environ Microbiol 2012, 78:3753-3755.

7. Alvarez J, Sáez JL, García N, Serrat C, Pérez-Sancho M, González S, Ortega MJ, Gou J, Carbajo L, Garrido F, Goyache J, Domínguez L: Management of an outbreak of brucellosis due to B. melitensis in dairy cattle in Spain. Res Vet Sci 2011, 90:208-211.

8. Muendo EN, Mbatha PM, Macharia J, Abdoel TH, Janszen PV, Pastoor R, Smits HL: Infection of cattle in Kenya with Brucella abortus biovar 3 and Brucella melitensis biovar 1 genotypes. Trop Anim Health Prod 2012, 44:17-20.

9. Probert WS, Schrader KN, Khuong NY, Bystrom SL, Graves MH: Real-time multiplex PCR assay for detection of Brucella spp., $B$. abortus, and $B$. melitensis. J Clin Microbiol 2004, 42:1290-1293.

10. Bounaadja L, Albert D, Chénais B, Hénault S, Zygmunt MS, Poliak S, Garin-Bastuji B: Real-time PCR for identification of Brucella spp.: a comparative study of IS711, bcsp31 and per target genes. Vet Microbiol 2009, 137:156-164.

11. Matero P, Hemmilä H, Tomaso H, Piiparinen H, Rantakokko-Jalava K, Nuotio L, Nikkari S: Rapid field detection assays for Bacillus anthracis, Brucella spp., Francisella tularensis and Yersinia pestis. Clin Microbiol Infect 2011, 17:34-43.

12. Bricker BJ, Halling SM: Differentiation of Brucella abortus bv. 1, 2, and 4, Brucella melitensis, Brucella ovis, and Brucella suis bv. 1 by PCR. J Clin Microbiol 1994, 32:2660-2666.

13. García-Yoldi D, Marín CM, de Miguel MJ, Muñoz PM, Vizmanos JL, López-Goñi l: Multiplex PCR assay for the identification and differentiation of all Brucella species and the vaccine strains Brucella abortus S19 and RB51 and Brucella melitensis Rev1. Clin Chem 2006, 52:779-781.

14. López-Goñi I, García-Yoldi D, Marín CM, de Miguel MJ, Barquero-Calvo E, Guzmán-Verri C, Albert D, Garin-Bastuji B: New Bruce-ladder multiplex PCR assay for the biovar typing of Brucella suis and the discrimination of Brucella suis and Brucella canis. Vet Microbiol 2011, 154:152-155.

15. Redkar R, Rose S, Bricker B, DelVecchio V: Real-time detection of Brucella abortus, Brucella melitensis and Brucella suis. Mol Cell Probes 2001, 15:43-52.

16. Foster JT, Okinaka RT, Svensson R, Shaw K, De BK, Robison RA, Probert WS, Kenefic $L$, Brown WD, Keim P: Real-time PCR assays of single-nucleotide polymorphisms defining the major Brucella clades. J Clin Microbiol 2008, 46:296-301.

17. Gopaul KK, Koylass MS, Smith CJ, Whatmore AM: Rapid identification of Brucella isolates to the species level by real time PCR based single nucleotide polymorphism (SNP) analysis. BMC Microbiol 2008, 8:86.

18. Whatmore AM, Perrett LL, MacMillan AP: Characterisation of the genetic diversity of Brucella by multilocus sequencing. BMC Microbiol 2007, 7:34.

19. Ririe KM, Rasmussen RP, Wittwer $C T$ : Product differentiation by analysis of DNA melting curves during the polymerase chain reaction. Anal Biochem 1997, 245:154-160.

20. Akey JM, Sosnoski D, Parra E, Dios S, Hiester K, Su B, Bonilla C, Jin L, Shriver MD: Melting curve analysis of SNPs (MCSNP): a gel-free and inexpensive approach for SNP genotyping. Biotechniques 2001, 30:358-367. 
21. Gundry CN, Vandersteen JG, Reed GH, Pryor RJ, Chen J, Wittwer CT: Amplicon melting analysis with labeled primers: a closed-tube method for differentiating homozygotes and heterozygotes. Clin Chem 2003, 49:396-406.

22. Wittwer CT, Reed GH, Gundry CN, Vandersteen JG, Pryor RJ: High-resolution genotyping by amplicon melting analysis using LCGreen. Clin Chem 2003, 49:853-860.

23. Tong SY, Giffard PM: Microbiological applications of high-resolution melting analysis. J Clin Microbio/ 2012, 50:3418-3421.

24. Perng $C L$, Chen HY, Chiueh TS, Wang WY, Huang CT, Sun JR: Identification of non-tuberculous mycobacteria by real-time PCR coupled with a high-resolution melting system. J Med Microbiol 2012, 61:944-951.

25. Touati A, Peuchant O, Jensen JS, Bébéar C, Pereyre S: Direct detection of macrolide resistance in Mycoplasma genitalium in France from clinical specimens using real-time PCR and melting curve analysis. J Clin Microbiol.

26. Lee TH, Wu TS, Tseng CP, Qiu JT: High-resolution melting molecular signatures for rapid identification of human papillomavirus genotypes. PLoS One 2012, 7:e42051.

27. Costa JM, Cabaret O, Moukoury S, Bretagne S: Genotyping of the protozoan pathogen Toxoplasma gondii using high-resolution melting analysis of the repeated B1 gene. J Microbio/ Methods 2011, 86:357-363.

28. Heideman DA, Lurkin I, Doeleman M, Smit EF, Verheul HM, Meijer GA, Snijders PJ, Thunnissen E, Zwarthoff EC: KRAS and BRAF mutation analysis in routine molecular diagnostics: comparison of three testing methods on formalin-fixed, paraffin-embedded tumor-derived DNA. J Mol Diagn 2012, 14:247-255.

29. Vaclavikova R, Ehrlichova M, Hlavata I, Pecha V, Kozevnikovova R, Trnkova M, Adamek J, Edvardsen H, Kristensen VN, Gut I, Soucek P. Detection of frequent $A B C B 1$ polymorphisms by high-resolution melting curve analysis and their effect on breast carcinoma prognosis. Clin Chem Lab Med 2012, 50:1999-2007.

30. Seipp MT, Herrmann M, Wittwer $\subset$ : Automated DNA extraction, quantification, dilution, and PCR preparation for genotyping by high-resolution melting. J Biomol Tech 2010, 21:163-166.

31. Swen JJ, Baak-Pablo RF, Guchelaar HJ, van der Straaten T: Alternative methods to a TaqMan assay to detect a tri-allelic single nucleotide polymorphism rs757210 in the HNF1 $\beta$ gene. Clin Chem Lab Med 2011, 50:279-284

32. Winchell JM, Wolff BJ, Tiller R, Bowen MD, Hoffmaster AR: Rapid identification and discrimination of Brucella isolates by use of real-time PCR and high-resolution melt analysis. J Clin Microbiol 2010, 48:697-702.

33. Reed $\mathrm{GH}$, Kent JO, Wittwer $\mathrm{CT}$ : High-resolution DNA melting analysis for simple and efficient molecular diagnostics. Pharmacogenomics J 2007 8:597-608.

34. Kagkli DM, Folloni S, Barbau-Piednoir E, Van den Eede G, Van den Bulcke M: Towards a pathogenic Escherichia coli detection platform using multiplex $\mathrm{SYBR}^{\otimes}$ Green Real-time PCR methods and high resolution melting analysis. PLOS One 2012, 7:e39287.

35. Seipp MT, Pattison D, Durtschi JD, Jama M, Voelkerding KV, Wittwer CT: Quadruplex genotyping of F5, F2 and MTHFR variants in a single closed tube by High-Resolution amplicon Melting. Clin Chem 2008, 54:108-115.

36. Whatmore AM, Shankster SJ, Perrett LL, Murphy TJ, Brew SD, Thirlwall RE, Cutler SJ, MacMillan AP: Identification and characterization of variablenumber tandem-repeat markers for typing of Brucella spp. J Clin Microbiol 2006, 44:1982-1993.

37. Wattam AR, Foster JT, Mane SP, Beckstrom-Sternberg SM, Beckstrom-Sternberg JM, Dickerman AW, Keim P, Pearson T, Shukla M, Ward DV, Williams KP, Sobral BW, Tsolis RM, Whatmore AM, O'Callaghan D: Comparative phylogenomics and evolution of the Brucellae reveal a path to virulence. J Bacterio/ 2014, 196:920-930.

38. Audic S, Lescot M, Claverie JM, Cloeckaert A, Zygmunt MS: The genome sequence of Brucella pinnipedialis B2/94 sheds light on the evolutionary history of the genus Brucella. BMC Evol Biol 2011, 11:200
39. Gopaul KK, Sells J, Bricker BJ, Crasta OR, Whatmore AM: Rapid and reliable single nucleotide polymorphism-based differentiation of Brucella live vaccine strains from field strains. J Clin Microbiol 2010, 48:1461-1464.

40. Gee JE, De BK, Levett PN, Whitney AM, Novak RT, Popovic T: Use of $16 \mathrm{~S}$ rRNA gene sequencing for rapid confirmatory identification of Brucella isolates. J Clin Microbiol 2004, 42:3649-3654.

doi:10.1186/1756-0500-7-903

Cite this article as: Gopaul et al:: Development and assessment of multiplex high resolution melting assay as a tool for rapid single-tube identification of five Brucella species. BMC Research Notes 2014 7:903.

\section{Submit your next manuscript to BioMed Central and take full advantage of:}

- Convenient online submission

- Thorough peer review

- No space constraints or color figure charges

- Immediate publication on acceptance

- Inclusion in PubMed, CAS, Scopus and Google Scholar

- Research which is freely available for redistribution

Submit your manuscript at www.biomedcentral.com/submit
C) BioMed Central 